\title{
A Survey of Automatic Teller Machine Usage across the Adult Life Span

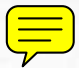

WENDY A. ROGERS, ${ }^{1}$ University of Georgia, Athens, Georgia, ELIZABETH F. CABRERA ${ }^{2}$ and NEFF WALKER, Georgia Institute of Technology, Atlanta, Georgia, D. KRISTEN GILBERT, ${ }^{3}$ University of Memphis, Memphis, Tennessee, and ARTHUR D. FISK, Georgia Institute of Technology, Atlanta, Georgia

The purpose of this study was to analyze automatic teller machine (ATM) usage across the adult life span. We conducted an extensive survey of 9000 people in the Memphis and Atlanta metropolitan areas. Approximately 17\% of those people responded. The survey assessed detailed demographic information, experience with technology in general, experience specifically related to ATMs, problems and dislikes with ATMs, and reasons that people do not use ATMs. The survey provided a valuable set of data. First, we have detailed information about the demographics and individual characteristics of ATM users and nonusers; importantly, these data are stratified across the adult life span. In addition, we know the likes and dislikes of ATM users and the types of problems they typically have using ATMs. Moreover, we have a detailed analysis of why adults of all ages may choose not to use ATMs. Training and design implications of these data are discussed.

\section{INTRODUCTION}

New technologies emerge in our society on a regular basis. Whether or not these technologies remain and are successful depends on the degree to which they are adopted by the members of society. A version of automatic teller machines (ATMs) was introduced in 1969 (Mauldin, Sutherland, \& Hofmeister, 1978). Mauldin et al. stated that by 1976 "'more than 4600 ATMs were reported in operation in the United States and growing in excess of 100 units a month" (p. 41). Currently there are probably tens of thousands of ATMs throughout the world. Such growth suggests that ATMs are a successful new tech-

\footnotetext{
${ }^{1}$ Requests for reprints should be sent to Wendy A. Rogers, Department of Psychology, University of Georgia, Athens, GA 30602-3013.

${ }^{2}$ Now at Universidad Carlos III, Madrid, Spain.

${ }^{3}$ Now at Pepperdine University, Malibu, California.
}

nology that has been adopted by members of society. The purpose of our study was to determine what characteristics identify individuals who use ATMs and how often, where, and for what transactions they use them. We also addressed the problems and difficulties users have with ATMs. In addition, we sought to determine why some people choose not to use ATMs. Perhaps most important, we assessed these variables across the adult life span, which enabled us to determine age-related differences (or lack thereof).

\section{Age Differences}

McNally and Abernathy (1989) reported that there is one major advantage for banks when individuals opt to use ATMs: "The cost of each transaction is lower when the ATM is used as opposed to a live teller" (p. 82). The benefit to 
banks is so substantial that McNally and Abernathy conducted a study in which they gave away approximately $\$ 1200$ per day for five weeks in bonuses to ATM users. Such motivation on the part of banks clearly illustrates their interest in having as many people as possible take advantage of ATM technology.

It has been suggested, however, that older individuals are less likely to use ATMs (Gilly \& Zeithaml, 1985; Zeithaml \& Gilly, 1987). Gilly and Zeithaml (1985) reported that only $15 \%$ of adults over age 65 used an ATM at all (compared with $43 \%$ of adults below 65 ) and that only $4 \%$ conducted more than half of their banking business at an ATM (compared with 14\% of other adul ts). Thus, at least in 1985, a substantial portion of older adults did not use ATMs. One of the goals of the present study was to determine. whether, in 1994, this continued to be the case. Moreover, we designed our study to assess why older adults choose not to use ATMs and whether they might be amenable to using them in the future.

\section{Training and Design Considerations}

Adams and Thieben (1991) conducted a study in which they trained older adults (over age 50) to use ATMs. They discovered that the type of training provided (e.g., a demonstration, plus practice making selections, plus learning the types of actions carried out on ATMs) affected the success of using an ATM. Banks typically provide little, if any, training, so individuals must learn how to use the ATM on their own.

Hatta and Iiyama (1991) assessed how successfully individuals could use an ATM without instruction (i.e., with only the information printed on the ATM screen). They discovered that the success rate for the first try was only $69 \%$ for deposits, $58 \%$ for withdrawals, and $53 \%$ for transferring funds between accounts. Moreover, although performance improved with practice, performance was still not perfect even after the third trial.

Both these studies point to the need to train individuals how to use ATMs. Furthermore, these results are informative for the designers of
ATMs. For example, Hatta and liyama (1991) suggested that entries should be correctable, appropriate on-line instructions should be provided, and the sequence of operations should be flexible. Design and training considerations were also a focus of the present study. An analysis of the difficulties encountered by users of all ages can provide guidance to ATM designers. In addition, such an analysis can serve to focus the ATM training needs of individuals across the adult life span.

\section{Overview of Study}

We conducted an extensive survey of ATM use and nonuse by individuals across the adult life span. The survey method was chosen to allow data collection from a large number of individuals at a relatively low cost, to reduce interviewer biases, and because the feeling of anonymity on the part of the respondent encourages open responding. However, there are potential limitations of this method, such as response biases and mismatches between self-report and actual behavior (see Fowler, 1988, and Judd, Smith, \& Kidder, 1991, for more details on survey methods).

Nevertheless, the data obtained from the survey served many purposes. First, they provided a detailed database of information about the types of individuals who use ATMs and the types who do not, information that can be used to predict the type of individual who is most likely to use an ATM. Second, we obtained a representation of the usage patterns for adults of all ages; that is, we could better understand how, when, why, and how often individuals use ATMs. Importantly, we could determine whether such usage patterns differ across the adult life span. Third, we gained a thorough understanding of the types of problems people encounter when using ATMs, data that are invaluable for the designers of new ATMs. Fourth, the survey of nonusers clarified why individuals choose not to use ATMs and whether, if provided with the opportunity and perhaps training, these individuals would be willing to use ATMs. This information is directly relevant to the developers and 
marketers of ATMs (e.g., banks). Finally, these data served as a springboard for future research on the development of training programs and design recommendations for the developers and users of ATMs.

\section{METHOD}

\section{Participants}

Questionnaires were mailed to 4500 individuals over age 18 in the metropolitan area of Atlanta, Georgia, and to 4500 individuals over age 18 in the metropolitan area of Memphis, Tennessee. Names were chosen randomly from automobile registration lists and telephone lists. Of the 9000 surveys mailed, 1562 were returned, for a total response rate of $17 \%$ ( $20 \%$ response rate in Atlanta and $14 \%$ response rate in Memphis). Survey respondents included 384 young adults, 445 middle-aged adults, 233 young-old adults, and 445 old adults (55 respondents did not list their age). Comparisons with the census data for each city are presented in Table 1. To summarize, our representation of men and women was close to the census; we had an underrepresentation of African Americans; our sample was more educated and had a higher household income than reportget 3 ;. icensus; and we had an overrepresentation of oldtit adults.

\section{Procedure}

The questionnaire consisted of three sections. The first section, which all respondents answered, asked for detailed demographic information, use of technology in general, use of computers, amount of banking done (in general and at an ATM), ownership of an ATM card, and use of an ATM card. The second section was answered only by ATM users and contained questions about usage patterns, specific problems encountered when using an ATM, and estimations

TABLE

Demographics of City Samples in Comparison with Census Data (Data are Percentages)

\begin{tabular}{lrrrr}
\hline & $\begin{array}{c}\text { Atlanta } \\
\text { Census }\end{array}$ & $\begin{array}{c}\text { Atlanta } \\
\text { Sample }\end{array}$ & $\begin{array}{c}\text { Memphis } \\
\text { Census }\end{array}$ & $\begin{array}{c}\text { Memphis } \\
\text { Sample }\end{array}$ \\
\hline Age (years) & & & & \\
Young (<35) & 42.0 & 23.6 & 38.5 & 28.0 \\
Middle-aged (35-54) & 38.3 & 30.7 & 36.3 & 27.9 \\
Young-old (55-64) & 9.2 & 15.7 & 10.6 & 15.1 \\
Old (65+) & 10.6 & 29.9 & 14.3 & 29.0 \\
Race & & & & \\
Caucasian & 63.0 & 92.0 & 57.6 & 86.2 \\
African American & 34.0 & 7.3 & 40.3 & 12.1 \\
Other & 3.6 & 2.8 & 2.1 & 3.5 \\
Sex & & & & 47.1 \\
Male & 48.0 & 41.0 & 47.8 & 52.9 \\
Female & 52.0 & 59.0 & 52.2 & 6.3 \\
Income & & & & 28.2 \\
\&10,000 & 11.1 & 3.7 & 19.2 & 29.5 \\
\$10,000-\$24,999 & 21.3 & 18.3 & 27.3 & 22.7 \\
\$25,000-\$49,999 & 35.7 & 28.3 & 32.2 & 4.8 \\
\$50,000-\$74,999 & 18.9 & 28.7 & 13.4 & 8.6 \\
\$75,000-\$99,999 & 6.9 & 8.7 & 4.0 & 4.9 \\
\$100,000+ & 5.9 & 12.3 & 3.9 & 17.5 \\
Education & & & & 34.6 \\
Some high school & 9.1 & 2.9 & 25.0 & 23.6 \\
High school diploma & 28.3 & 16.1 & 27.6 & 19.2 \\
Some college & 21.5 & 29.5 & 26.8 & \\
Bachelor's degree & 19.6 & 26.5 & 13.3 & 6.9 \\
Graduate degree & 8.8 & 24.8 & & \\
\hline & & & & \\
\hline
\end{tabular}


of difficulty levels for different ATM functions. The third section was answered only by nonusers and contained questions about their reasons for not currently using an ATM, their interest in using one in the future, and their willingness to be trained to use an ATM. (The complete questionnaire is available from the first author.)

The questionnaire was mailed to the individuals along with a cover letter explaining the purpose of the survey. Respondents were given the option of entering their name for a drawing of a gift certificate to a local restaurant. Fifty gift certificates were given to respondents from the Atlanta sample and 50 to respondents from the Memphis sample.

\section{RESULTS AND DISCUSSION}

\section{City Differences}

Only minor differences were found in demographics between the Atlanta and Memphis samples. Members of the Atlanta sample had slightly more education, and their income was slightly higher. With regard to the ATM questions, responses to only six questions significantly differed between the two samples. Interestingly, two of the questions related to the cost of using an ATM. Atlanta users were less satisfied with the cost of using an ATM, and Atlanta nonusers were more likely to rate cost as an important reason for not using an ATM.

To determine whether the cost differences between the two cities were real or imagined, we randomly chose five banks in each city and assessed how much they charged users for each transaction. None of the banks charged a fee for making a deposit or withdrawal using their machines, and the cost of making a withdrawal from another bank's machine was equivalent in the two cities. However, Atlanta banks were more likely to charge customers for getting a credit card cash advance and for responding to a balance inquiry. (Note that there may be costof-living differences between the two cities.) Given the minimal differences between the two samples, the data were combined for the remaining analyses.

\section{Users versus Nonusers}

We asked the respondents if they had ever had an ATM card. The percentage answering yes was $95 \%, 92 \%, 83 \%$ and $67 \%$, respectively, for the young, middle-aged young-old, and old adults. In addition, we asked if they currently used an ATM card, to which $86 \%$ young, $73 \%$ middleaged, 54\% young-old, and 33\% old adults answered yes. Respondents were classified as users or nonusers on the basis of their answer to the latter question. Note that there were many more people who had an ATM card than there were current users, and this was especially true for the older groups. Thus the fact that individuals were not using ATMs was not simply attributable to their not having access to ATM cards; instead, many of the nonusers were choosing not to use their card, for whatever reason (possibilities are discussed later in this paper). ATM providers should be less concerned with providing access to ATM cards and more concerned with getting card owners to use their cards.

One of our central questions concerned whether users and nonusers had different demographics and characteristics (e.g., experience with technology). Demographic comparisons are presented in Figure 1. We conducted $t$-test comparisons between user groups for each age group. For the young adults, the users were better educated, $t(381)=2.20, p<.05$, and had a higher income, $t(363)=2.44, p<.05$. For the middleaged adults, the users were slightly younger than the nonusers, $t(443)=2.23, p<.05$. There were no significant group differences for the young-old adults. For the old adults, users were younger than nonusers, $t(443)=6.50, p<.01$; users rated their health better than did nonusers, $t(432)=2.01, p<.05$; and users were better educated than nonusers, $t(441)=2.54, p<.01$. Thus the most user/nonuser differences were observed for the oldest adults.

The user/nonuser differences for technology and computer use are presented in Table 2. All differences between the groups were significant 

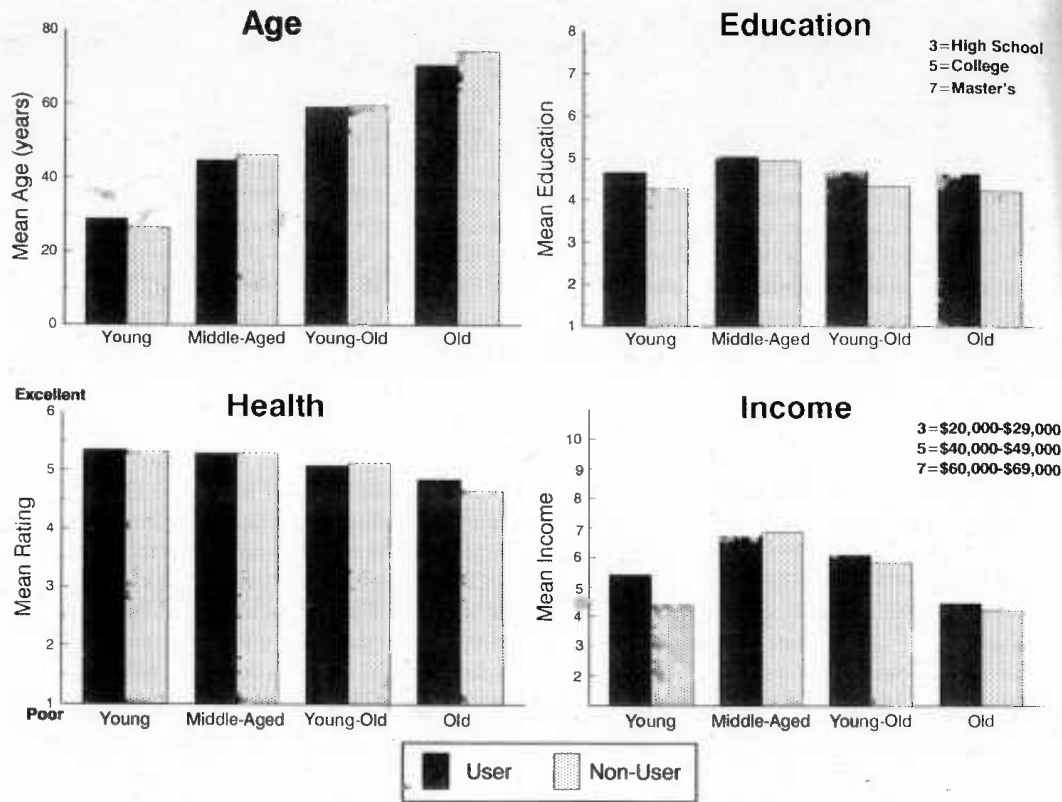

Figure 1. Demographic comparisons of users and nonusers for each age group.

at the .05 level except for computer experience for the middle-aged adults $(p<.07)$. Thus we can conclude that for all age groups, ATM users take advantage of more technologies, have more experience with computers, and feel more comfortable using computers.

We conducted a hierarchical regression analysis to determine if we could predict ATM usage

TABLE 2

Use of Technology and Computers: ATM Users vs Non-users (Percentages)

\begin{tabular}{lcccc}
\hline & $\begin{array}{c}\text { Young } \\
(<35)\end{array}$ & $\begin{array}{c}\text { Middle-Aged } \\
(35-54)\end{array}$ & $\begin{array}{c}\text { Young-OId } \\
(55-64)\end{array}$ & $\begin{array}{c}\text { Old } \\
(65+)\end{array}$ \\
\hline $\begin{array}{l}\text { Use of technology } \\
\quad \text { ATM users }\end{array}$ & $10.3(2.0)$ & $9.6(2.3)$ & $8.2(2.3)$ & $6.9(2.4)$ \\
$\quad \begin{array}{l}\text { Nonusers } \\
\text { Experience with computers }\end{array}$ & $9.0(2.1)$ & $8.3(2.3)$ & $7.2(2.9)$ & $4.8(2.6)$ \\
$\quad$ ATM users & $5.1(1.3)$ & $4.7(1.5)$ & $4.6(1.4)$ & $3.7(1.8)$ \\
$\quad \begin{array}{l}\text { Nonusers } \\
\text { Comfortable using computers }\end{array}$ & $4.6(1.5)$ & $4.4(1.8)$ & $3.9(1.9)$ & $2.5(1.8)$ \\
$\quad$ ATM users & $4.9(1.4)$ & $4.6(1.5)$ & $4.3(1.5)$ & $3.7(1.9)$ \\
$\quad$ Nonusers & $4.4(1.6)$ & $4.2(1.8)$ & $3.7(1.9)$ & $2.5(1.8)$ \\
\hline
\end{tabular}

"Highest possible score was 13 , corresponding to 13 differenl types of technology that the respondent might have used (e.g., microwave, answering machine). 'S Scale was 1 (strongly disagree) to 6 (stronghy agree). 
on the basis of demographic and technology use variables. The dependent variable was ATM use (yes or no) and the predictor variables were age, race, sex, marital status, work status, education, income, health, profession, language, number of people in home, disability status, dwelling type, technology use, computer experience, computer comfort, and computer use (e.g., how often). Use of technology accounted for $\mathbf{2 0 \%}$ of the variance, age accounted for an additional $4 \%$, and computer use accounted for an additional $1 \%$. None of the other predictor variables accounted for an additionally significant amount of variance. The regression analysis supports the trend reported earlier: Whether an individual takes advantage of technology is clearly related to whether he or she is likely to use an ATM.

Use of technology accounted for significantly more variance in ATM usage than simply the age of the individual. This result suggests that people tend to think of ATMs as a type of technology, and this influences the degree to which they use them. People who use microwaves, VCRs, answering machines, and so on are more likely also to use ATMs. The implication is that in order to increase the use of ATMs, banks may wish to deemphasize their technological nature. That is, rather than promoting ATMs as a new technology, it might be better to emphasize the simplicity and ease of using ATMs.

\section{ATM Users}

A series of questions were directed to ATM users, some of which were designed to assess usage patterns. We were also interested in whether the patterns differed across age groups. First, to ensure that our users were not novices, we asked them how long they had had an ATM card. The vast majority responded that they had had their ATM card for at least one year $(93.9 \%, 97.3 \%$, $97.6 \%$, and $100 \%$, respectively, for the young, middle-aged, young-old, and old adults). We also asked how many times they had to use their ATM card before they felt completely comfortable. The majority responded that comfortability was reached after one to four times $(81.3 \%$,
$79.5 \%, 79.7 \%$, and $70.1 \%$, respectively, for the young, middle-aged, young-old, and old adults). Interestingly, 9\% of the old adults responded that they never felt comfortable using the ATM (compared with $1.8 \%-2.4 \%$ of the other age groups). Thus, even for a group of experienced ATM users, some older adults continue to feel uncomfortable using an ATM. This population would be ideal for an ATM training program; they are willing to use an ATM, yet they feel uncomfortable doing so. An ATM tutorial would allow them to gain mastery of the ATM and, perhaps, increase their ATM usage. At the very least, training would lessen their discomfort with using the ATM.

Responses to the usage pattern questions are presented in Table 3 . The younger adults are more likely to use their ATM card more than once per week, whereas the older adults reported using it more than once per month. In terms of ATM locations, all age groups use the ATM most frequently at the bank, followed by a drive-up window or at the grocery store. However, there were significant age differences for all the locations except for the bank (all ps < .01). The young and middle-aged adults tended to use nonbank ATM locations more often than did the two older age groups.

All age groups use the ATM most frequently for withdrawals and rarely to make payments. However, there were significant age differences for withdrawals, balance inquiries, and transfers between accounts (all $p s<.01$ ). Young and middle-aged adults used an ATM for these transactions more frequently than did the two older groups.

Respondents were also asked questions about actual or perceived difficulties with ATMs. These data are presented in Table 4. Concerning problems with ATMs, young, middle-aged, and young-old adults rated having to wait in line to use the machine highest in difficulty, whereas old adults rated being able to see the screen well highest. Thus in order to design systems to meet the needs of users, ATM designers may wish to speed up the process for the younger users (in 
TABLE 3

Usage Patterns for Each Age Group

\begin{tabular}{|c|c|c|c|c|}
\hline & $\begin{array}{l}\text { Young } \\
(<35)\end{array}$ & $\begin{array}{l}\text { Middle-Aged } \\
\quad(35-54)\end{array}$ & $\begin{array}{l}\text { Young-Old } \\
(55-64)\end{array}$ & $\begin{array}{l}\text { Old } \\
(65+)\end{array}$ \\
\hline \multicolumn{5}{|l|}{$\begin{array}{l}\text { How often do you use your ATM card? } \\
\text { (percentages) }\end{array}$} \\
\hline Never & 0.0 & 1.5 & 10 & 4.7 \\
\hline Once a year & 1.2 & 3.9 & 4.8 & 4.1 \\
\hline Every 6 months & 1.5 & 5.8 & 5.6 & 8.1 \\
\hline Once a month & 14.0 & 13.9 & 16.7 & 14.2 \\
\hline More than once a month & 14.9 & 14.2 & 11.9 & 29.7 \\
\hline Once a week & 35.6 & 33.0 & 38.9 & 26.4 \\
\hline More than once a week & 32.2 & 27.0 & 20.6 & 12.8 \\
\hline Once a day & 0.6 & 0.6 & 0.0 & 0.0 \\
\hline \multicolumn{5}{|c|}{$\begin{array}{l}\text { I use ATMs at the following locations } \\
\text { (Scale: } 1=\text { never, } 6 \text { = always; means and standard deviations): }\end{array}$} \\
\hline Bank & $4.6(1.1)$ & $4.5(1.2)$ & $4.5(1.5)$ & $4.5(1.6)$ \\
\hline Drive-up window & $3.2(1.6)$ & $2.6(1.6)$ & $2.1(1.6)$ & $2.2(1.6)$ \\
\hline Grocery Store & $2.7(1.5)$ & $2.3(1.4)$ & $2.2(1.4)$ & $2.2(1.6)$ \\
\hline Freestanding (e.g., parking lot) & $2.5(1.6)$ & $2.1(1.4)$ & $1.8(1.4)$ & $1.7(1.3)$ \\
\hline Mall & $2.4(1.3)$ & $2.0(1.2)$ & $1.8(1.1)$ & $1.4(0.9)$ \\
\hline Airport & $1.6(1.1)$ & $1.7(1.2)$ & $1.4(0.7)$ & $1.3(0.9)$ \\
\hline \multicolumn{5}{|c|}{$\begin{array}{l}\text { How often do you use the ATM for the following transactions? } \\
\text { (Scale: } 1=\text { never, } 6=\text { always; means and standard deviations) }\end{array}$} \\
\hline Withdrawals & $5.1(0.9)$ & $4.7(1.3)$ & $4.6(1.3)$ & $4.4(1.4)$ \\
\hline Balance inquiries & $3.1(1.7)$ & $2.9(1.7)$ & $2.5(1.7)$ & $2.4(1.6)$ \\
\hline Deposits & $2.2(1.5)$ & $2.3(1.5)$ & $2.1(1.6)$ & $2.0(1.5)$ \\
\hline Transfers between accounts & $1.9(1.5)$ & $1.8(1.3)$ & $1.4(1.1)$ & $1.4(1.1)$ \\
\hline $\begin{array}{l}\text { Cash advances from } \\
\text { credit card }\end{array}$ & $1.5(1.0)$ & $1.5(1.0)$ & $1.5(1.1)$ & $1.4(1.0)$ \\
\hline Make payments & $1.1(0.4)$ & $1.1(0.5)$ & $1.1(0.7)$ & $1.1(0.7)$ \\
\hline
\end{tabular}

this case those under 65) and improve the visibility of the system for the oldest users. It is important to note that none of the average ratings for any of the problems was higher than 3.0 on a scale of 1 (never a problem) to 6 (always a problem). Hence nonusers should be encouraged that users of all ages appear to be able to use ATMs with relatively few problems. This does not suggest that improvements and training would not be helpful; however, it does suggest that using the ATM may not be as problematic as some nonusers might believe.

We also asked respondents to rate their actual or perceived difficulty with performing different transactions on an ATM. All the age groups rated making payments as the most difficult; this is interesting because, as we reported earlier, all of them also claimed that they hardly ever used an ATM to make payments. Either users do not use the ATM to make payments because they think it is too difficult, or they think making payments is difficult because they rarely do so. In either case, training users how to make payments at the ATM may convince them that it is not difficult and can save them time.

The overall pattern of difficulty ratings was identical across age groups. Adults of all ages perceive making withdrawals and balance inquiries to be easy and perceive making deposits, cash advances, transfers, and payments to be progressively harder. However, for transfers, cash advances, withdrawals, and balance inquiries, there was a significant age difference in the overall difficulty rating (all $p s<.05$ ); the two 


\begin{tabular}{|c|c|c|c|c|}
\hline & $\begin{array}{l}\text { Young } \\
(<35)\end{array}$ & $\begin{array}{l}\text { Middle-Aged } \\
\text { (35-54) }\end{array}$ & $\begin{array}{l}\text { Young-Old } \\
(55-64)\end{array}$ & $\underset{(65+)}{\text { Old }}$ \\
\hline \multicolumn{5}{|c|}{$\begin{array}{l}\text { Here are some common problems people have in using ATMs. } \\
\text { For each of the following, rate how often it is a problem for you. } \\
\text { (scale: } 1=\text { never, } 6=\text { always; means and standard deviations) }\end{array}$} \\
\hline $\begin{array}{l}\text { Having to wait in line to use } \\
\text { the machine }\end{array}$ & $3.0(1.2)$ & $2.8(1.1)$ & $2.5(1.1)$ & $2.3(1.0)$ \\
\hline Machine working too slowly & $2.5(1.3)$ & $2.3(1.2)$ & $1.8(1.0)$ & $1.5(0.8)$ \\
\hline Remembering to record my transaction & 2.5 (1.3) & $2.2(1.3)$ & $1.9(1.3)$ & $2.1(1.4)$ \\
\hline Machine running out of money & $2.2(1.2)$ & $2.2(1.1)$ & $2.2(1.1)$ & $1.9(0.9)$ \\
\hline Being unable to see the screen well & $2.1(1.2)$ & $2.1(1.2)$ & $2.2(1.3)$ & $2.5(1.6)$ \\
\hline Putting the card in the wrong way & $1.9(1.2)$ & $1.9(1.0)$ & $1.8(1.1)$ & $1.7(0.9)$ \\
\hline Getting the amount of money I want & $1.7(1.2)$ & $1.6(1.1)$ & $1.6(1.2)$ & $1.8(1.6)$ \\
\hline Determining if the ATM is working & $1.7(1.0)$ & $1.8(1.0)$ & $1.5(0.8)$ & $1.6(1.0)$ \\
\hline Getting the machine to read my card & $1.6(1.0)$ & $1.8(1.2)$ & $1.5(1.0)$ & $1.8(1.4)$ \\
\hline Forgetting secret code & $1.5(0.9)$ & $1.5(0.9)$ & $1.2(0.6)$ & $1.3(0.7)$ \\
\hline Reaching the slots & $1.5(1.0)$ & $1.5(1.0)$ & $1.3(0.9)$ & $1.4(1.0)$ \\
\hline Machine keeping card & $1.4(0.6)$ & $1.5(0.7)$ & $1.3(0.6)$ & $1.4(0.6)$ \\
\hline $\begin{array}{l}\text { Understanding how to do what I } \\
\text { want on the ATM }\end{array}$ & $1.3(0.9)$ & $1.6(1.2)$ & $1.6(1.2)$ & $1.9(1.5)$ \\
\hline \multicolumn{5}{|c|}{$\begin{array}{l}\text { Rate how difficult you think the following transactions are to complete. } \\
\text { Please give an opinion even if you have not performed the transaction. } \\
\text { (Scale: } 1=\text { easy to use, } 6=\text { hard to use; means and standard deviations) }\end{array}$} \\
\hline Make payments & $2.9(1.4)$ & $2.5(1.4)$ & $2.7(1.4)$ & $3.0(1.6)$ \\
\hline Transfers between accounts & $2.4(1.4)$ & $2.2(1.3)$ & $2.5(1.4)$ & $2.8(1.5)$ \\
\hline Cash advances from credit card & $2.2(1.3)$ & $2.1(1.3)$ & $2.2(1.3)$ & $2.7(1.7)$ \\
\hline Deposits & $2.1(1.2)$ & $2.0(1.2)$ & $2.2(1.3)$ & $2.1(1.4)$ \\
\hline Balance inquires & $1.4(0.9)$ & $1.4(1.0)$ & $1.7(1.1)$ & $1.6(1.2)$ \\
\hline Withdrawals & $1.1(0.4)$ & $1.2(0.7)$ & $1.2(0.5)$ & $1.3(0.8)$ \\
\hline
\end{tabular}

older groups rated the transactions as more difficult than did the two younger groups.

\section{Nonusers}

A different series of questions was directed to non-ATM users, which were designed to determine why they were nonusers. In addition, we wished to determine whether any of these individuals might be interested in using an ATM in the future. The data for these questions are presented in Table 5. For the young adults, the most highly rated reason for not using ATMs was that they did not feel safe using them. Thus improving the safety (or perceived safety) of ATMs might increase usage. Efforts to improve the safety of ATMs might include locating them in safer places (such as grocery stores). Safety was also indicated as an important reason for the other age groups (second highest); however, the middle-aged, young-old, and older adults all rated "prefer to deal with people instead of machines" higher as a reason not to use ATMs. Many of the older adults appear to prefer the more traditional method of banking with a teller. The more personal, interactive, and safe ATMs become, the more likely it is that some older individuals will be willing to use them.

We conducted a one-way ANOVA for each of the questions listed in Table 5 to determine if there were significant age differences. Significant differences were observed for the following: (1) "Do not see a need for the service," $F(3,492)$ $=3.15, p<.02$; a multiple-range test revealed that the young-old group was significantly 


\begin{tabular}{|c|c|c|c|c|}
\hline & $\begin{array}{l}\text { Young } \\
(<35)\end{array}$ & $\begin{array}{l}\text { Middle-Aged } \\
\quad(35-54)\end{array}$ & $\begin{array}{l}\text { Young-Old } \\
(55-64)\end{array}$ & $\underset{(65+)}{\text { Old }}$ \\
\hline \multicolumn{5}{|c|}{$\begin{array}{l}\text { Please rate the importance of each item as a reason you choose not to use an ATM. } \\
\text { (Scale: } 1 \text { unimportant, } 6 \text { = very important; means and standard deviations) }\end{array}$} \\
\hline I do not feel safe when using an ATM. & $4.2(2.0)$ & $4.3(1.9)$ & $4.5(2.1)$ & $4.1(2.2)$ \\
\hline $\begin{array}{l}\text { I am concerned about keeping track of } \\
\text { transactions (e.g.; balancing account). }\end{array}$ & $4.0(2.0)$ & $3.9(2.0)$ & 2.2) & $3.6(2.2)$ \\
\hline I prefer to deal with people instead of machines. & $3.6(2.1)$ & $4.5(1.8)$ & $4.7(1.9)$ & $4.7(2.0)$ \\
\hline I am concerned about the cost of using the system. & $3.5(2.1)$ & $3.2(2.2)$ & $3.4(2.1)$ & $2.5(1.9)$ \\
\hline I do not see a need for the service. & $3.2(1.5)$ & $3.5(1.8)$ & $3.7(2.0)$ & $3.0(2.2)$ \\
\hline do not think the system is private enough. & $3.0(2.1)$ & $3.3(2.0)$ & $3.4(2.1)$ & $3.3(2.2)$ \\
\hline I do not trust the accuracy of the system. & $2.6(1.5)$ & $3.1(1.9)$ & $3.0(2.0)$ & $2.7(1.9)$ \\
\hline I do not know how the system works. & $2.0(1.6)$ & $2.3(1.6)$ & $2.4(1.9)$ & $2.4(1.9)$ \\
\hline I do not know how to use the system. & $2.0(1.6)$ & $2.2(1.6)$ & $2.4(1.9)$ & $2.4(2.0)$ \\
\hline \multicolumn{5}{|l|}{$\begin{array}{l}\text { Would you like to use an ATM? } \\
\text { (percentages) }\end{array}$} \\
\hline Yes & 22.4 & 14.3 & 16.7 & 6.3 \\
\hline \multicolumn{5}{|c|}{$\begin{array}{l}\text { If training were offered in the use of ATMs, would you be interested in learning to use them? } \\
\text { (percentages) }\end{array}$} \\
\hline Yes & 18.4 & 12.4 & 21.0 & 9.6 \\
\hline
\end{tabular}

different from the old group. Thus the young-old adults rated not needing the service higher than did the old adults. (2) "Prefer people to machines," $F(3,481)=4.63, p<.01$; a multiplerange test revealed that the young group was significantly different from all the other groups. Young adults were less likely to consider this an important reason for not using ATMs. (3) "Concerned about the cost," $F(3,416)=5.67, p<.01$; a multiple-range test revealed that the old group was significantly different from all the other groups. The older group was less concerned with cost than were the younger groups.

In response to the question "Would you like to use an ATM?" the percentage of respondents answering yes ranged from $6.3 \%$ to $22.4 \%$. The question "If training were offered, would you be interested to learn?" yielded yes answers ranging from $9.6 \%$ to $18.4 \%$. Thus a reasonable number of nonusers would like to use ATMs and would be willing to attend a training program to learn how. Interestingly, for young and middleaged adults, more people would like to use an ATM than were willing to attend a training pro- gram. Presumably these individuals do not feel the need for training on this system. However, for the two older groups, more people would be willing to use an ATM if they were first trained.

\section{CONCLUSIONS}

As was observed by Zeithaml and Gilly (1987), younger adults are significantly more likely to use ATMs relative to older adults. However, only $15 \%$ of their older sample used ATMs, whereas $33 \%$ of our respondents over age 65 reported using ATMs. In the years since the Zeithaml and Gilly (1987) study, ATMs have become more available. In addition, ATMs may have become more acceptable to older adults as a means of banking (or they may have become more accepting of technology). In either case, there remains a majority of older individuals who choose not to use ATMs.

Concerns about using ATMs do not appear to be insurmountable. When asked if they would be interested in using an ATM, $6.3 \%$ to $22.4 \%$ of the nonusers indicated that they would. Moreover, 
the range of individuals willing to learn to use ATMs (through training) was $9.6 \%$ to $21 \%$ (see Table 5). More individuals in the two older groups were potentially willing to use ATMs if training were provided. One of the goals of our research is to provide those individuals who wish to use ATMs the opportunity to do so. The facilitation of ATM use by adults of all ages can be accomplished through a combination of design improvements and the development of training procedures. The implications of the present data for these efforts are discussed in the next section.

\section{Training Implications}

One of the clear implications of the present study is the need to train individuals to use ATMs (see also Adams \& Thieben, 1991; Hatta \& Iiyama, 1991). At best, most banks provide only a brief pamphlet about how to use their ATM. Our results suggest that this training (or lack thereof) is insufficient for successful use of ATMs. For example, $9 \%$ of the old adult ATM users claimed that they have never felt comfortable using an ATM. These are individuals who have been using an ATM card and yet continue to be apprehensive about using the machine. In addition, nonusers (of all ages) stated that they would be willing to attend a training program to learn how to use an ATM. Thus even individuals who do not currently use ATMs would be willing to learn. Of particular interest were the youngold and old adults, more of whom would be more willing to use an ATM if training were provided than if they had to learn to use one on their own.

The optimum training method remains an empirical question. However, such a training method should be brief, easy to use, and yet comprehensive. Ideally the training could be administered by a bank officer in a nonstressful environment in about $15 \mathrm{~min}$. In a related study, older adults expressed concern about learning to use ATMs while others are waiting (Rogers, Gilbert, \& Cabrera, in press).

Training should be focused on the reportedly more difficult transactions, such as transfers be- tween accounts and payments. In the not-toodistant future, ATMs will probably be used for functions such as paying bills and purchasing tickets. Consequently, it will be important for users to learn how to take advantage of all the available functions.

Training issues to be resolved in future research include (a) the optimal type of training material (e.g., on-line tutorial, augmented textual instructions, or perhaps a pictorial guide) and whether the utility of training materials differs across individuals of varying ages or abilities; (b) the amount of training required; (c) retention of information across time (e.g., if trained at the bank, will the person remember what to do at the ATM several weeks later?); and (d) transfer of training across different types of ATMs.

\section{Design Implications}

Design improvements for ATMs can occur at two levels: surface-level (hardware) improvements and conceptual-level (software) improvements. In terms of surface-level improvements, older users stated that they often had difficulty seeing the ATM screen. Antiglare screens, bigger text, better alignment of options to buttons, and better location with respect to the sun could improve the usability of the system. Users of all ages complained about having to wait in line to use the ATM, and the younger respondents also complained about the machine working too slowly. ATM designers should focus some of their energies on maximizing turnaround time at ATMs and, within the ATM system, improving efficiency so as to minimize wait time.

Conceptual-level design improvements should also be considered. The younger age groups expressed concern about remembering to record their transactions, which represents a challenge to designers in the development of future systems. The fact that use of technology was the best predictor of ATM use suggests that designers should attempt to reduce the technological nature of ATMs (i.e., focus on user-friendliness). To illustrate, many of the older nonusers expressed a preference for dealing with people. 
Hence improvement in the personal and interactive nature of ATMs might result in use by nonusers as well as increased use by current users. As is often the case, design improvements made with special populations in mind will improve the overall functionality of the system for all ussers.

The present survey has provided a valuable set of data. First, we obtained detailed information about the demographics and individual characteristics of ATM users and nonusers; importantly, these data are stratified across the adult life span. In addition, we now know the usage patterns of ATM users and the types of problems they typically have using ATMs. Moreover, we have a detailed analysis of why adults of all ages choose not to use ATMs. All of this information can provide insight to the developers of training programs as well as to system designers.

\section{ACKNOWLEDGMENTS}

This research was supported in part by a grant from $\mathrm{Na}$ tional Institutes of Health (National Institute on Aging) Grant P50 AG117I5 under the auspices of the Center for Applied Cognitive Research on Aging (one of the Edward R. Roybal Centers for Research on Applied Gerontology).

\section{REFERENCES}

Adams, A. S., Thieben, K. A. (1991). Automatic teller machines and the older population. Applied Ergonomics, 22, 85-90.

Fowler, F. 3. (1988). Sunvey research methods. Newbury Park, CA: Sage.

Gilly, M. C. \& Zeithaml, V. A. (1985). The elderiy consumer and adoption of technologies. Joumal of Consumer Research, 12, 353-357.
Hatta, K., \& Iiyama, Y. (1991). Ergonomic study of automatic teller machine operability. International Journal of $\mathrm{Hu}$. man-Computer Interaction, 3, 295-309.

Judd, C. M., Smith, E. R., \& Kidder, L. H. (1991). Research methods in social relations. Chicago: Holt, Rinehart \& Winston.

McNally, K. A., \& Abernathy, W. B. (1989). Effects of monetary incentives on customer behavior: Use of automatic teller machines (ATMs) by low frequency users. Joumal of Organizarional Behavior Management, 10, 79-91.

Kaul'n, C. R., Sutherland, J. C., \& Hofmeister, J. F. (1978). Operant attitude segmentation and marketing decisions. Operant Subjectivity, 1, 38-50.

Rogers, W. A., Gilbert, D. K., \& Cabrera, E. F. (in press). An analysis of automatic teller machine usage by older adults A structured interview approach. Applied Ergonomics.

Zeithaml, V.A., \& Gilly, M. C. (1987). Characteristics affecting the acceptance of retail technologies: A comparison of ei derly and nonelderly consumers. Joumal of Retailing, 63 49-68.

Wendy A. Rogers is an assistant professor of psychology at the University of Georgia. She received her M.S. (1989) and Ph.D. (1991) degrees in experimental psychology from the Georgia Institute of Technology.

Elizabeth F. Cabrera is a visiting professor in the Business Department at Universidad Carlos III in Madrid. She received M.S. (1993) and Ph.D. (1995) degrees in industrial organizational psychology from Georgia Institute of Technology.

Neff Walker is an assistant professor at the Georgia Institute of Technology. He received his Ph.D. in psychology from Columbia University in 1983.

D. Kristen Gilbert is an assistant professor of psychology in the Social Science Division at Pepperdine University. She received her M.S. (1992) and Ph.D. (1995) degrees in experimental psychology from the University of Memphis.

Arthur D. Fisk is a professor in both the general-experimental and engineering psychology programs at the Georgia Institute of Technology in the School of Psychology and is coordinator of the engineering psychology program. He received a Ph.D. from the University of Illinois in 1982.

Date received: June 21, 1994

Date accepted: February 13, 1995 